\title{
SOME CONSIDERATIONS REGARDING THE EXTERNALISATION OF THE ECONOMIC AGENTS SERVICES
}

\author{
Filimon Stremțan, Ph D, Full Professor, filimonstremtan@yahoo.com \\ "1 Decembrie 1918" University, Alba Iulia, Romania \\ Moisă Claudia, LecturerPhD Student, claudiapatrut@yahoo.com \\ “1 Decembrie 1918” University, Alba Iulia, Romania
}

\begin{abstract}
The specialisation of some companies in carrying out services for the industries lead to an process of services externalisation, with beneficial effects over the activities of the companies that are producing goods and services and also on stimulating the business market. Externalisation does not imply non inclusion in the activity of the company of those activities that are considered as being subsidiary, that are not strictly necessary or are not directly involved in obtaining results for the main activities of the company. In this context the company appeals to the market in order to benefit from the services or the activities that were externalised.
\end{abstract}

A big part of the services for enterprises initially appeared as specialized activities destined to sustain production, they were integrated in the firm's processes. Thus, there is an internalization process of the services that requires the immobilization of huge labor and important investments to ensure the technical and material base necessary for the sustainment of the services' activities.

Simultaneously to the enterprises' development the administration of these services has become more and more difficult especially when the services are repeated with a low frequency. They competed to a growth of the expenses which are difficult to allocate on products so there will be an accurate quantification of each fabricated item.

The specialization of companies in services for enterprises led to a services' externalization process with good results on the activity of material producers and services providers and on the rousing of the market. The externalization does not include the activities considered secondary, which means they are not strictly necessary or are not directly involved in the results of the company's main activity. In this context the company turns to the market in order to profit from the services and activities that were externalized.

The advantages of the services' externalization include:

$>$ The growth of the work productivity on the background of eliminating the labor involved in providing services, which is considered indirect productive labor;

$>$ The possibility of providing services which have an occasional necessity without needing to immobilize the staff and the equipment adherent to the services;

$>$ The superior quality of the services due to the providing company's specialization;

$>$ The simplification of the managerial process on the background of the number of operation's reduction as a result of giving up a part of the internal services.

Despite these advantages enterprises have kept a big part of the internalized services. In order to take the decision to externalize some services it's important to take into account the transition costs which result from turning to the market in order to collaborate with firms 
with the same business. The solution to turn to the market for covering the service necessities has a logical economic support. To produce for itself the necessary services the company must buy from the market the information, expertise and qualifications that it lacks considering its specialization for a certain field of activity.

The decision to externalize the services is based on two criteria which aim the specificity and the use frequency of the service. When the service is specific without any other companies on the market that need it, it's possible that the interest of the providers of services is low and consequently the costs are high. In such cases the alternative for internalizing the services is preferred. Also, if the use frequency is high it can be less expensive to organize it as a separate autonomous activity. In chart no. 1 are reflected the decisions that a company can make regarding the externalization of services, by taking into account the two criteria: the use frequency and the specificity of the service.

Chart no. 1 Decisions regarding the services' externalization depending on the specificity and the use frequency of the service

\begin{tabular}{|c|c|c|c|}
\hline \multirow{2}{*}{$\begin{array}{c}\text { The use } \\
\text { frequency }\end{array}$} & \multicolumn{3}{|c|}{ The specificity of the service } \\
\cline { 2 - 3 } & Low specificity & Medium specificity & High specificity \\
\hline Low & $\begin{array}{c}\text { Regular purchasing } \\
\text { of the market }\end{array}$ & $\begin{array}{c}\text { Contractual relations with } \\
\text { neutral assistance }\end{array}$ & \\
\cline { 3 - 4 } & & $\begin{array}{c}\text { Long term bilateral } \\
\text { contracts }\end{array}$ & Internalization \\
\hline
\end{tabular}

In case the specificity of the service is low you can turn to its buying of the market, regardless of the high or the low use frequency because it's thought there is a large number of providers that offer these services to a relatively high number of enterprises.

If the specificity of the service is medium and the use frequency is low it is necessary to establish a firm contractual relation with the service provider, so there is a guarantee of complying with all the demands regarding the offered service. Because the service is not common, a third party's assistance it's often necessary, which can be either an enterprise that uses that service or a specialized consultant. In case the specificity is medium and the use frequency is high, it is necessary to have a long term contractual relation that will ensure for both sides the success of the transaction.

If the specificity of the service is high and the use frequency is low you can turn to a contractual relation with neutral assistance or you can proceed to internalizing the service. In case both the specificity and the use frequency are high, the most efficient solution is to organize that activity with your own resources, because turning to the market can be expensive.

Starting from the decision regarding the internalization and externalization of the services, the companies can choose from one of the following options for organizing the services:

- To organize departments specialized in providing services at the company's level (market research, transportation etc). This alternative requires the internalization of the services by intergrating them in the firm's operations.

- Starting an autonomous entity as a subsidiary of the firm, that has financial and organizational autonomy. This solution pursues to offer efficiency to the provider's activity and the activity of the beneficiary, offering at the same time to the beneficiary the certainty those services will be provided at an optimum quality and price. 
- Turning to the services of independent providers. This solution requires the full externalization of the services, while the relations between the two companies are contractual. The firms can choose diverse combinations of the solutions above, depending on its necessities.

\section{Externalizing the services - a possible solution for having a competitive advantage on the market}

Associating the services with the offered products is a challenge for the management of each company because it is necessary to restructure the processes that take place inside the firm and it's necessary to have a major strategic change from the transactional management to a relational management. At the same time for making the products and the services associated to them, the firms have to turn to certain services. These services can lead to the growth of the company's income, but also to a high level of client's satisfaction. The services can lead to the creation of "that unique sale offer", which makes a substantial difference between the products of different companies.

For the management of each firm associating the services with the offered products is a challenge because it is necessary to restructure the processes that take place inside the firm and it's necessary to have a major strategic change from the transactional management to a relational management. At the same time for making the products and the services associated to them, the firms have to turn to certain services. O big part of the services for enterprises were initially created as specialized activities, destined to sustain production and was integrated in the production process. Thus, there is an internalization process of the services which requires the immobilization of a large volume of labor and important investments for the technical and material ground necessary to sustain the services.

The externalization's policies have to have at their base the obtainment of a competitive advantage either regarding the costs or regarding the flexibility of the economic agent or the obtainment of a difference from the competition.

According to M. Porter, the competitive advantage can't be understood if we look at the company as a whole. It can be obtained from one or more activities of the firm, starting with projection and continuing with provisioning, production, delivery, the assistance offered for the products after they are delivered etc. Each of these activities can contribute to a relative costs position favorable for the firm or they can create a ground for differences.

In order to underline each source for the competitive advantage, M. Porter proposes a systemic approach based on splitting the company's activities in relevant strategic activities, a split which is known under the name of value chain. This value chain can be integrated in a more complex system of activities, called value system (see chart no.2).

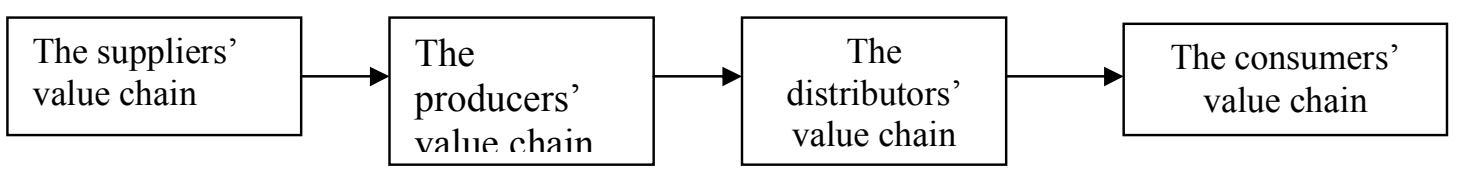

\section{Chart no. 2 The value system for a enterprise}

(Source: Porter, M,. - The Competitive Advantage, Teora Publishing House, Bucharest, 2001)

The suppliers for goods producers have their own value chains, which create and deliver the producer's entries and can influence its performance in many ways. Also the distributors add value to the products which have effects on the competitivity of the producer. 
Finally, the product enters the consumer's value chain which offers a certain degree of utility. From the point of view of stabile relations and of the power relations the company's position in this system can contribute to getting a competitive advantage.

The company's value chain can be split in simple activities in order to allow the underlining of the contribution of each activity to the creation of the value and of the competitive advantage. Such activities could be:

- designing

- production

- depositing

- delivery

- marketing

- human resources administration (see chart no. 3)

The primary activities are activities which are directly related to the making of the product, the sale, the physical transfer to the buyer and also the after-sale assistance.

The support activities offer the primary activities a series of resources, like: material, human and technological resources. They contribute to the establishing of the product's value, and in the end it can result a value margin which represents the difference between the total value of the product and the costs of the primary and support activities.

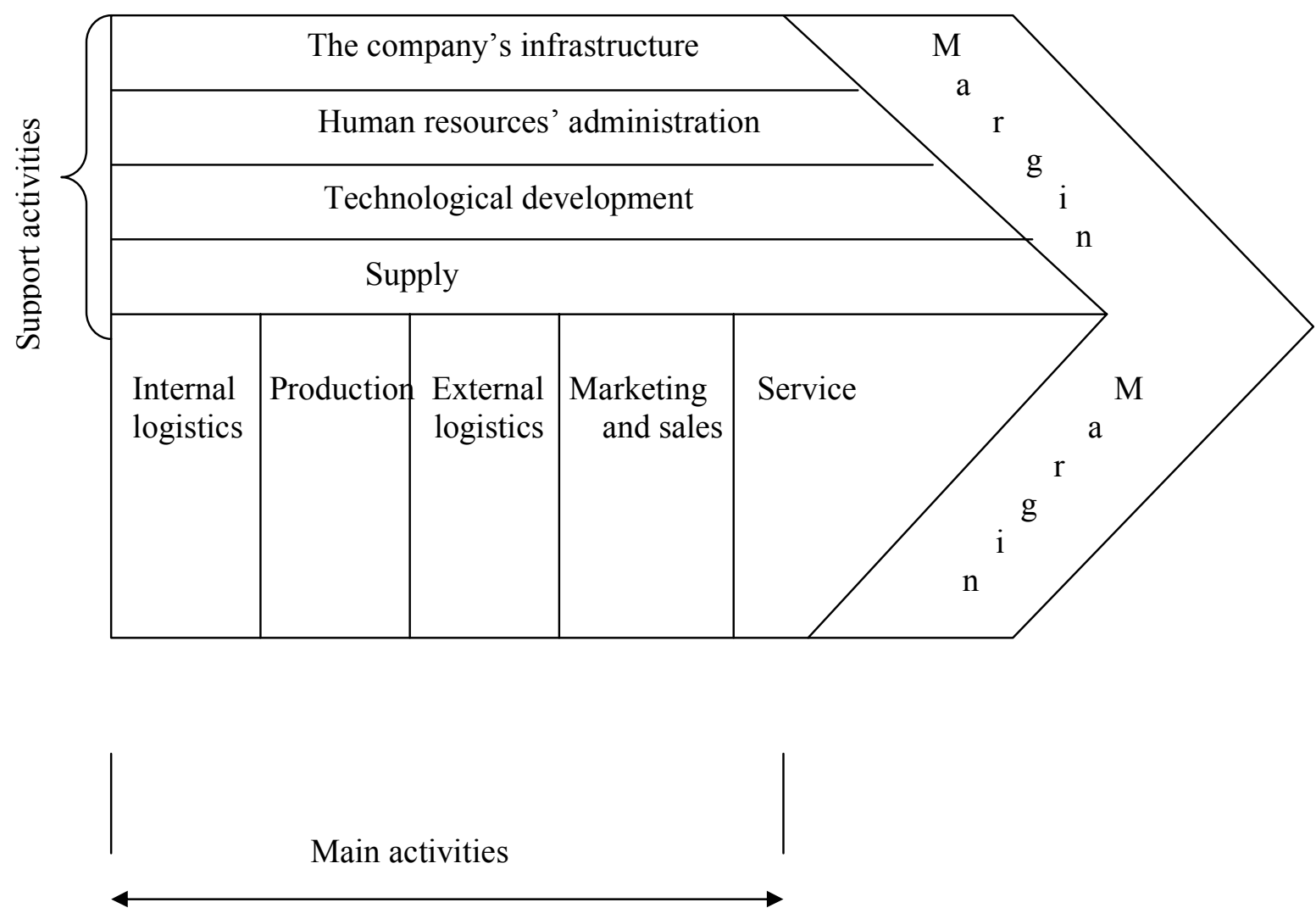

Chart. no. 3 The value's generic chain

(Source: Porter, M,. - The Competitive Advantage, Teora Publishing House, Bucharest, 2001

)

It can be seen that support activities represent providing services for the production activity and are decisive in creating the value of the products. Also, at the level of primary 
activities we can identify a whole series of service providing, from the logistics of the supplied merchandise to the logistics of the finished product, of the marketing and the service of these products.

All these service providing can be provided by specialized departments, but depending on certain strategic decisions made by the company's management a part of them can be externalized. These decisions must rely on lowering the costs by giving the services to providers with a high productivity, but they must also take into consideration the performance levels that will lead to the growth of the value for the client.

The decisions to externalize the services often rely on the strategic changes inside the organizations which have become more client-orientated. These organizations are permanently preoccupied with: diminishing the time it takes to answer to the client's requests, improving the quality of the products, promoting team work on a large scale and relations management on long term.

Shaping the respective trends led to a re-orientation of the firm's attention from using technical terms to measure the processes' performance to measuring them by using the level of client's satisfaction.

By analyzing the possible services' externalization policies, we can identify three main externalization strategies with specific objectives and motivations:

$\checkmark$ The voluntary services' externalization in order to have a growth in the competitivity of the company

$\checkmark$ The services' externalization as a necessity for the good serving of the clients

$\checkmark$ The services' externalization as a follow up to the adherence to voluntary standards

\section{Bibliography:}

1. Balaure,V. (coordonator) - Marketing, Ediția a 2-a. Ed. Uranus, Bucureşti, 2002

2. Constantin, C. - Teză de doctorat, Bucureşti, 2007

3. Cristureanu, C.- Economia invizibilului. Tranzacțiile internaționale cu servicii. Ed. All Beck, Bucureşti, 2004

4. Ioncică, M. - Economia serviciilor. Ed. Uranus, Bucurețti, 2006

5. Glais, M. - Les strategies Concurrentielles des Firmes. Ed. Litec, Paris, 1992

6. Oliva, R, Kallenberg, R, - Managing the transition from products to services. International Journal of Service Industry Management. Vol.14. Nr. 2. 2003

7. Porter, M. -Avantajul Concurențial, Ed. Teora, Bucureşti, 2001

8. Vandermerwe, S, Gilbert, D. - Internal Services: Gaps in Needs/Performance and prescriptions for effectiveness. International Journal of Services Industry Management. Vol. 2. Nr.1. 1991 
